\title{
Penerapan Model Pembelajaran Student Facilitator And Explaining Untuk Meningkatkan Hasil Belajar Siswa Pada Mata Pelajaran Matematika di Kelas V Sekolah Dasar Negeri 164 Pekanbaru
}

\author{
Ines Yuwandari ${ }^{1}$, Mimi Hariyani ${ }^{2}$ \\ ${ }^{1}$ Program Magister Pendidikan Madrasah Ibtidaiyah, Universitas Islam Negeri Sultan Syarif \\ Kasim Riau \\ ${ }^{2}$ Program Studi Pendidikan Guru Madrasab Ibtidaiyah, Islam Negeri Sultan Syarif Kasim \\ Riau \\ e-mail: Inesyuwandari@gmail.com
}

\begin{abstract}
This research aimed at increasing student learning achievement on Mathematics subject throughthe implementation of Student Facilitator and Explaining learning model at thefifth grade of State Elementary School 164 Pekanbaru. It was instigatedby the low of student learning achievement that could not pass the minimum standard of passing grade determined 75. It was a Classroom Action Research. The subjects of this research were the teachers and students. The objects were Student Facilitator and Explaining learning model and learning achievement. This research was conducted for two cycles, and every cycle comprised two meetings. Observation, learning achievement test, and documentation were the techniques of collecting the data. The technique of analyzing the data was Descriptive qualitative with percentage. Based on the research findings and data analyses,Student Facilitator and Explaining learning model could increase learning achievement. It could be seen from student learning achievement that the mean was 68.61 before the action with $47.22 \%$ classical mastery, and it was on poor category. After implementing Student Facilitator and Explaining learning model in the first cycle, student learning achievement mean increased to 73.88 with $66.66 \%$ classical mastery, and it was on enough category. In the second cycle, student learning achievement mean increased to 80.27 with $86.11 \%$ classical mastery, and it was on perfect category. Thus, Student Facilitator and Explaining learning model achieved success indicators that were expected at thefith grade of state of student school 164 Pekanbaru.
\end{abstract}

Kata kunci: Student Facilitator and Explaining, Learning Model, Student Learning Achievement.

\section{PENDAHULUAN}

Pendidikan merupakan usaha sadar dan terencana untuk mewujudkan suasana belajar dan proses pembelajaran agar peserta didik secara aktif mengembangkan potensi 
dirinya untuk memiliki kekuatan spiritual, keagamaan, pengendalian diri, kepribadian, kecerdasan, akhlak mulia serta keterampilan yang diperlukan dirinya, masyarakat, Bangsa dan Negara (Alex Sobur, 2003 : 268).

Secara umum belajar adalah berubah. Dalam hal ini belajar berarti usaha untuk mengubah tingkah laku. Jadi, belajar akan membawa suatu perubahan pada individuindividu yang belajar. Perubahan tersebut tidak hanya berkaitan dengan penambahan ilmu pengetahuan, tetapi juga berbentuk keterampilan dan sikap (Sardiman, 2007 : 21). Sekolah sebagai suatu lembaga pendidikan formal, secara sistematis telah merencanakan berbagai lingkungan, yakni lingkungan pendidikan yang menyediakan berbagai kesempatan bagi siswa untuk melakukan berbagai kegiatan pembelajaran sehingga para siswa memperoleh pengalaman. Sehingga segala aspek pengetahuan tersebut dapat diakses, sebagaimana firman Allah Subhanahu Wata'ala dalam surah Al-alaq ayat 1-5:
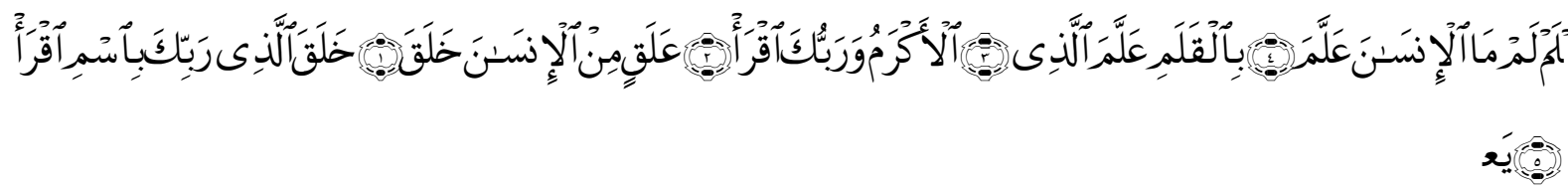

Artinya: (1) Bacalah dengan (menyebut) nama Tuhanmu yang Menciptakan. (2) Dia Telah menciptakan manusia dari segumpal darah. (3) Bacalah, dan Tuhanmulah yang Maha pemurah. (4) Yang mengajar (manusia) dengan perantaran kalam. (5) Dia mengajar kepada manusia apa yang tidak diketahuinya. (Q.S. Al-Alaq: 1-5).

Pembelajaran adalah proses dimana terjadi kegiatan belajar dan mengajar. Mengajar merupakan suatu usaha untuk menciptakan kondisi atau sistem lingkungan yang mendukung dan memungkinkan untuk berlangsungnya proses belajar. Sedangkan belajar adalah suatu proses yang dilakukan individu untuk memperoleh suatu perubahan tingkah laku yang baru secara keseluruhan, sebagian hasil pengalaman individu itu sendiri didalam interaksi dengan lingkungannya. Dalam proses pembelajaran guru berupaya mengubah masukan berupa siswa yang belum terdidik menjadi siswa yang terdidik, siswa yang belum memiliki pengetahuan tentang sesuatu, menjadi siswa yang memilki pengetahuan. Demikian pula siswa yang memiliki sikap, kebiasaan atau tingkah laku yang belum mencerminkan eksistensi dirinya sebagai pribadi baik, menjadi siswa yang memiliki sikap, kebiasaan dan tingkah laku baik. Jadi pembelajaran adalah suatu aktivitas yang dengan sengaja untuk memodifikasi berbagai kondisi yang diarahkan untuk tercapainya suatu tujuan yaitu terjadinya tujuan kurikulum (Mardiah Hayati, 2014 : 12-13).

Matematika merupakan salah satu bidang studi yang diajarkan di SD atau MI. Seorang guru SD atau MI yang akan mengajarkan matematika kepada siswanya, hendaklah mengetahui dan memahami objek yang akan diajarkannya, yaitu matematika. Matematika adalah salah satu disiplin ilmu yang diperlukan dalam kehidupan sehari-hari. Keuntungan apabila siswa belajar aktif adalah tanggapan dari sesuatu atau yang di kerjakan sendiri lebih sempurna, mudah direproduksi, dan pengertian yang diperoleh lebih jelas, setelah itu beberapa sifat watak terpimpin dapat dipupuk misalnya: hati-hati, rajin, tekun, tahan diuji, percaya pada diri sendiri, perasaan sosial dan sebagainya (Ramayulis, 1990 : 90 ).

Matematika merupakan ilmu yang mempelajari hubungan pola, bentuk dan struktur (Mimi dan Melly, 2013 : 1). Matematika di kenal sebagai ilmu deduktif, karena proses mencari kebenaran dalam matematika berbeda dengan ilmu pengetahuan alam dan ilmu pengetahuan sosial. Dengan demikian mata pelajaran Matematika sangatlah penting 
diajarkan di SD/MI untuk membekali siswa dengan cara berfikir secara logis, analisis dan kreatif, serta kemampuan bekerja sama untuk memecahkan masalah dalam kehidupan sehari-hari.

Sebelum peneliti menerapkan model pembelajaran student facilitator and explaining ternyata guru matematika kelas $\mathrm{V}$ sudah menerapkan model pembelajaran kooperatif tipeteams games tournament yang diyakini dapat mengatasi persoalan tersebut karena dengan menggunakan model pembelajaran kooperatif tipe teams games tournament pembelajaran akan lebih menarik karena menggunakan kartu yang dilakukan dalam bentuk permainan. Pada model pembelajaran kooperatif tipe teams games tournament siswa dikelompokkan dalam kelompok-kelompok kecil yang beranggotakan lima sampai enam orang siswa yang masing-masing anggotanya melakukan turnamen pada kelompoknya masing-masing (Mohammad Syarif S, 2015 : 56).

Berdasarkan kenyataan yang dijumpai di kelas V Sekolah Dasar Negeri 164 Pekanbaru Peneliti memilih kelas $\mathrm{V}$ yang akan dilakukan penelitian tindakan kelas dengan menggunakan Model pembelajaran Student Facilitator and Explaining. Hasil observasi dan wawancara peneliti dengan guru kelas $\mathrm{V}$ pada tanggal 08 Januari yang lalu yaitu ibu Karmila, S.Pd. Dimana beliau mengatakan bahwa hasil belajar siswa yang masih tergolong rendah 41,67\% yang belum mencapai KKM dikarenakan guru yang bersangkutan sudah berupaya memaksimalkan, mungkin dengan melakukan kegiatan belajar guru yang tidak menggunakan model pembelajaran yang bervariasi yang membuat siswa kurang aktif, malas mengerjakan tugas dan siswa menjadi pasif dalam proses pembelajaran.

Berdasarkan masalah tersebut peneliti menemukan gejala-gejala yang menunjukkan hasil belajar siswa dalam proses pembelajaran masih tergolong rendah pada mata pelajaran Matematika yaitu sebagai berikut: (1) dari 36 orang siswa hanya 17 orang siswa atau 47,22\% yang telah mencapai nilai KKM yang ditetapkan yaitu 75. (2) dari 36 orang siswa ada 19 orang siswa atau 52,77\% siswa masih sulit dalam menjawab soal ulangan dengan benar. (3) dari 36 orang siswa hanya 5 orang siswa atau 13,8\% yang mengajukan pertanyaan ketika diberikan kesempatan untuk bertanya oleh guru.

Berdasarkan latar belakang di atas, maka peneliti tertarik untuk melakukan suatu Penelitian Tindakan Kelas sebagai upaya dalam melakukan perbaikan terhadap proses pembelajaran Matematika dan peningkatan hasil belajar siswa dengan judul: Penerapan Model Pembelajaran Student Facilitator and Explaining untuk Meningkatkan Hasil Belajar Siswa pada Mata Pelajaran Matematika di Kelas V Sekolah Dasar Negeri 164 Pekanbaru.

Tujuan dari penelitian ini adalah untuk mendeskripsikan penerapan Model Pembelajaran Student Facilitator and Explaining dalam meningkatkan Hasil Belajar Siswa pada Mata Pelajaran Matematika di Kelas V Sekolah Dasar Negeri 164 Pekanbaru..

\section{METODOLOGI}

Penelitian ini adalah penelitian tindakan kelas. Penelitian dilaksanakan di kelas V Sekolah Dasar Negeri 164 Pekanbaru, pada semester dua. Adapun waktu penelitian pada bulan Februari tahun ajaran 2017/2018. Subjek dalam penelitian ini adalah siswa kelas V Sekolah Dasar Negeri 164 Pekanbaru dengan jumlah siswa 36 orang, yang mana terdiri dari 17 siswa laki-laki dan 19 siswa perempuan. Sedangkan yang menjadi objek dalam 
penelitian ini adalah meningkatkan hasil belajar siswa pada mata pelajaran Matematika dengan menggunakan Model Pembelajaran Student Facilitator and Explaining di kelas V Sekolah Dasar Negeri 164 Pekanbaru.

Penelitian yang dilaksanakan adalah Penelitian Tindakan Kelas. Penelitian tindakan kelas adalah suatu bentuk penelitian yang bersifat reklektif dengan melakukan tindakantindakan tertentu agar dapat memperbaiki atau meningkatkan praktik-praktik pembelajaran di kelas secara profesional (Masnur Muslich, 2011 : 9).

Langkah-langkah penelitian ini terdiri dari perencanaan tindakan, pelaksanaan tindakan, observasi dan refleksi. Empat langkah tersebut saling berkaitan dengan pelaksanaan penelitian tindakan kelas. Hubungan keempat tindakan tersebut pada bagan berikut:

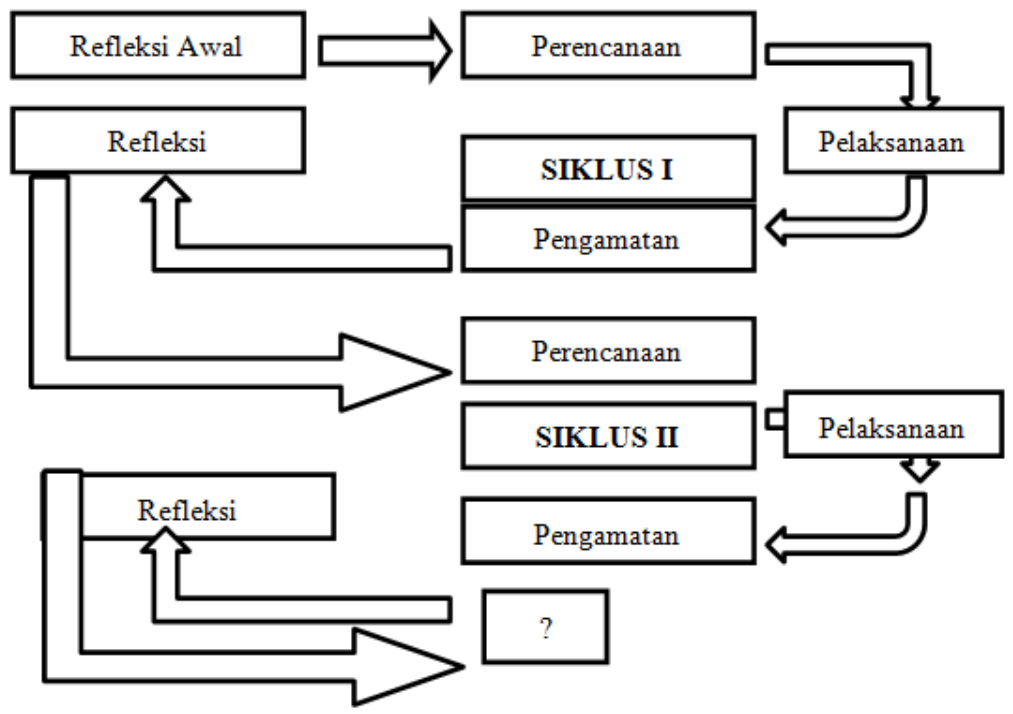

\section{Gambar 1. Siklus Penelitian}

Dalam tahap perencanaan atau persiapan tindakan ini, langkah-langkah yang dilakukan adalah sebagai berikut: (a) Menyusun Rencana Pelaksanaan Pembelajaran (RPP) berdasarkan silabus yang memuat penyesuaian Kompetensi Dasar (KD) dengan tindakan. (b) Mempersiapkan lembar observasi untuk mengamati aktivitas guru dan peserta didik. (c) Menentukan kolaborator sebagai observer.

Teknik pengumpulan data yang digunakan dalam penelitian ini adalah obaervasi, tes tertulis, dan dokumentasi. Metode observasi dilakukan untuk mengetahui bagaimana pembelajaran matematika yang berlangsung di kelas. Tes tertulis dilakukan untuk mengetahui seberapa fahamnya siswa dalam pelajaran matematika dengan mnggunakan model pembelajaran student facilitator and explaining. Dokumentasi ini dilakukan untuk mengetahui sejarah sekolah, keadaan guru dan siswa, sarana dan prasarana yang ada di Sekolah Dasar Negeri 164 Pekanbaru dan data tentang hasil belajar siswa.

Teknik analiasis lembar observasi penelitian ini adalah dengan menggunakan teknik analisis deskriptif. Teknik statistik deskriptif merupakan kegiatan statistik yang dimulai dari menghimpun data, menyusun atau mengukur data, mengelola data, menyajikan dan menganalisis data angka guna memberikan gambaran suatu gejala, peristiwa atau keadaan. Analisis deskriptif ini dilakukan untuk mengetahui gambaran data yang akan dianalisis. (a) Analisis data kualitatif, yaitu data yang berupa informasi yang berbentuk kalimat yang 
memberi gambaran tentang ekspresi siswa berkaitan dengan tingkat pemahaman terhadap suatu mata pelajaran, pandangan atau sikap siswa terhadap teknik belajar yang baru, aktivitas siswa mengikuti pelajaran, perhatian, antusias dalam belajar dan kepercayaan diri dapat dianalisis secara kualitatif. (b) Analisis data kuantitatif, yaitu data yang berupa angka (nilai skor) dapat dianalisis secara deskriptif. Misalnya mencari nilai rata-rata persentase keberhasilan, dan lain-lain (Kunandar, 2008 : 127).

Selain itu analisis deskriptif juga digunakan (Anas Sujiono, $2004: 43$ ) untuk menentukan keberhasilan aktivitas guru dan aktivitas siswa dalam bentuk mendemonstrasikan kegiatan selama proses pembelajaran diolah dengan menggunakan rumus presentase yaitu sebagai berikut:

$$
\mathrm{P}=\mathrm{F} / \mathrm{N} X 100 \%
$$

Keterangan :

$$
\begin{aligned}
& \mathrm{P}=\text { Angka Persentase Aktivitas Guru } \\
& \mathrm{F} \quad=\text { Frekuensi Aktivitas Guru } \\
& \mathrm{N} \quad=\text { Angka Persentase } \\
& 100 \%=\text { Bilangan tetap }
\end{aligned}
$$

Dalam buku (Suharsimi, 2006 : 246) menentukan kriteria penilaian tentang aktivitas guru dan siswa pada mata pelajaran Matematika, maka dilakukan pengelompokkan atas 4 kriteria penilaian yaitu sebagai berikut:

Tabel1.Interval Kategori Aktivitas Guru dan Aktivitas Siswa

\begin{tabular}{ll}
\hline Tingkat Pengguasaan & Predikat \\
\hline $76 \%$ s $/$ d $100 \%$ & Baik \\
$56 \%$ s/d $75 \%$ & Cukup Baik \\
$40 \%$ s $/$ d $55 \%$ & Kurang Baik \\
$<40 \%$ & Tidak Baik \\
\hline
\end{tabular}

Untuk Ketuntasan Hasil Belajar diukur dari ketuntasan klasikal. Untuk menghitung ketuntasan individu dan presentase ketuntasan klasikal, rumus yang digunakan yaitu:

Rumus Hasil Belajar

$\mathrm{Na}=\mathrm{Sp} / \mathrm{Sm} \times 100 \%$

Keterangan:

$\mathrm{Na}=$ Nilai Akhir

Sp $=$ Skor Perolehan

$\mathrm{Sm}=$ Skor Maksimal

Ketuntasan Klasikal

Untuk mengukur ketuntasan secara klasikal rumus yang digunakan yaitu :

$$
\text { Ketuntasan Klasikal }=\frac{\text { Jumlah Siswa yang Tuntas }}{\text { Jumlah Keseluruhan Siswa }} \times 100 \%
$$


Adapun kriteria penilaian menurut (Riduan, 2009 : 30) hasil belajar siswa dalam proses pembelajaran Matematika dapat terlihat pada tabel berikut:

Tabel2.Kategori Hasil Belajar

\begin{tabular}{ll}
\hline Interval (\%) & Kategori \\
\hline $90-100$ & Sangat Sempurna \\
$80-89$ & Sempurna \\
$70-79$ & Cukup \\
$60-69$ & Kurang \\
$<60$ & Sangat Kurang \\
\hline
\end{tabular}

\section{HASIL DAN PEMBAHASAN}

\section{Hasil Penelitian}

Diketahui bahwa pada siklus I (pertemuan pertama dan kedua) aktivitas guru tergolong "Cukup Baik", dengan persentase 70,83\% berada pada rentang 56-75 Pada siklus II (pertemuan ketiga dan keempat) meningkat menjadi 89,58\% tergolong "Baik", berada pada rentang 76-100 lebih jelas dapat dilihat pada tabel berikut ini:

Tabel 3.Rekapitulasi Aktivitas Guru Siklus I Dan Siklus II

\begin{tabular}{ccccccc}
\hline $\begin{array}{c}\text { Aspek } \\
\text { Yang } \\
\text { Diamati }\end{array}$ & $\begin{array}{c}\text { Pertemuan } \\
\mathbf{1}\end{array}$ & $\begin{array}{c}\text { Pertemuan } \\
\mathbf{2}\end{array}$ & $\begin{array}{c}\text { Rata- } \\
\text { rata }\end{array}$ & $\begin{array}{c}\text { Pertemuan } \\
\mathbf{3}\end{array}$ & $\begin{array}{c}\text { Pertemuan } \\
\mathbf{4}\end{array}$ & $\begin{array}{c}\text { Rata- } \\
\text { rata }\end{array}$ \\
\hline $\begin{array}{c}\text { Aktivitas } \\
\text { Guru }\end{array}$ & $66,66 \%$ & $75 \%$ & $70,83 \%$ & $87,5 \%$ & 91,66 & $89,58 \%$ \\
\hline
\end{tabular}

Sumber: Data Rekapitulasi Aktivitas Guru, Tahun 2018

Perbandingan persentase aktivitas guru dengan penerapan model pembelajaran student facilitator and explaining pada siklus I dan siklus II juga dapat dilihat pada histogram berikut:

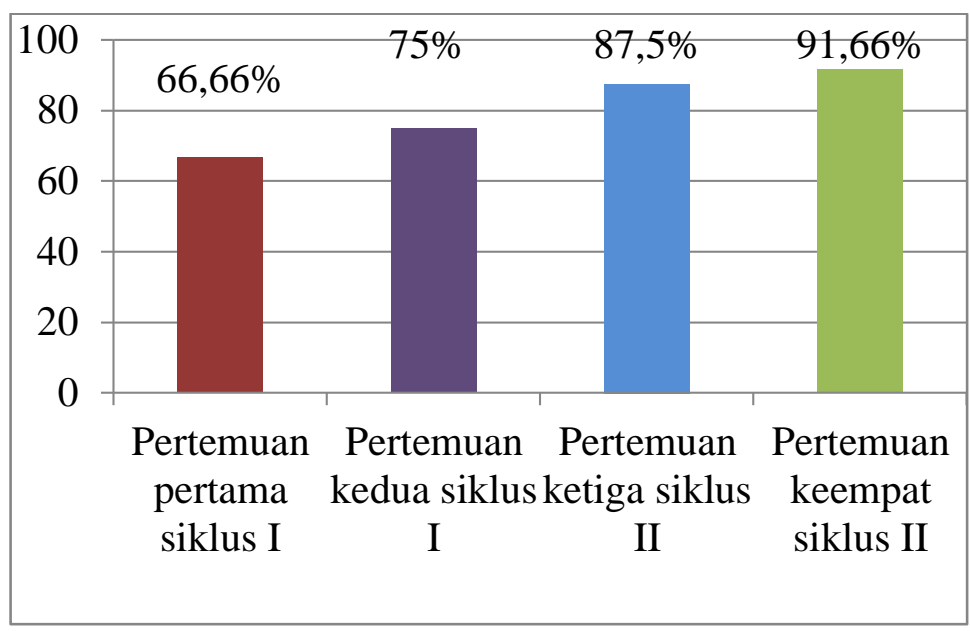

Gambar 2.Grafik Rekapitulasi Perbandingan Aktivitas Guru padaSiklus I (Pertemuan Pertama dan kedua) dan Siklus II (Pertemuan Ketiga dan Keempat) 


\section{Aktivitas Siswa}

Persentase aktivitas siswa selama kegiatan belajar mengajar dengan menggunakan model pembelajaran student facilitator and explaining pada pertemuan pertama siklus I presentase aktivitas siswa secara klasikal memperoleh 64,81\% dengan rentang nilai 56-75 tergolong "Cukup Baik", pada pertemuan kedua siklus I presentase aktivitas siswa memperoleh 69,44\% dengan rentang nilai 56-75 tergolong "Cukup Baik", sedangkan pada pertemuan ketiga siklus II terjadi peningkatan sebesar 76,85\% dengan rentang nilai 76-100 tergolong "Baik", pada perteuan keempat siklus II persentase mencapai 92,59\% dengan rentang nilai 76-100 tergolong "Baik".

Agar lebih jelas peningkatan aktivitas siswa dapat dilihat pada tabel berikut ini:

Tabel 4. Rekapitulasi Aktivitas Siswa Pada Siklus I dan Siklus

II

\begin{tabular}{ccccccc}
\hline $\begin{array}{c}\text { Aspek } \\
\text { Yang } \\
\text { Diamati }\end{array}$ & $\begin{array}{c}\text { pertemuan } \\
\mathbf{1}\end{array}$ & $\begin{array}{c}\text { Pertemuan } \\
\mathbf{2}\end{array}$ & $\begin{array}{c}\text { Rata- } \\
\text { rata }\end{array}$ & $\begin{array}{c}\text { Pertemuan } \\
\mathbf{3}\end{array}$ & $\begin{array}{c}\text { Pertemuan } \\
\mathbf{4}\end{array}$ & $\begin{array}{c}\text { Rata- } \\
\text { rata }\end{array}$ \\
\hline $\begin{array}{c}\text { Aktivitas } \\
\text { Siswa }\end{array}$ & $64,81 \%$ & $69,44 \%$ & $\begin{array}{c}67,12 \\
\%\end{array}$ & $76,85 \%$ & $92,59 \%$ & 84,02 \\
& & & & & & $\%$
\end{tabular}

Sumber: Data Hasil Olahan Penelitian, Tahun 2018

Perbandingan aktivitas siswa pada siklus I dan siklus II pada tiap pertemuan juga dapat dilihat pada histogram berikut:

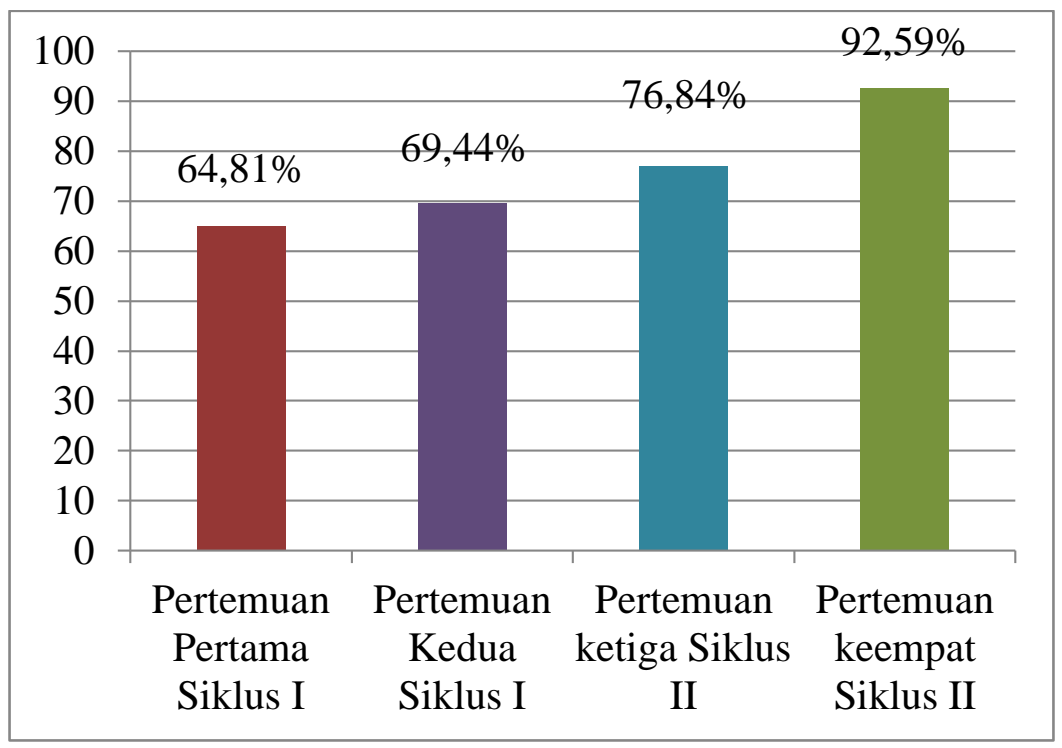

Gambar 3. Grafik Rekapitulasi Perbandingan Aktivitas Siswa pada Siklus I (Pertemuan Pertama dan kedua) dan Siklus II (Pertemuan Ketiga dan Keempat)

\section{Hasil Belajar}

Perbandingan hasil belajar siswa dilihat dari sebelum tindakan, siklus I dan siklus II secara jelas dapat dilihat pada tabel berikut: 


\section{Tabel 5.Rekapitulasi Hasil Belajar Siswa dari Sebelum Tindakan, Siklus I dan Siklus II}

\begin{tabular}{cccc}
\hline Tes & JumlahSiswa & $\begin{array}{c}\text { JumlahSiswa } \\
\text { Yang Tuntas }\end{array}$ & $\begin{array}{c}\text { JumlahSiswa } \\
\text { Yang } \\
\text { TidakTuntas }\end{array}$ \\
\hline SebelumTindakan & 36 & $17 / 47,22 \%$ & $19 / 52,77 \%$ \\
Siklus I & 36 & $24 / 66,66 \%$ & $12 / 33,33 \%$ \\
Siklus II & 36 & $31 / 86,11 \%$ & $5 / 13,88 \%$ \\
\hline
\end{tabular}

Sumber: Data Rekapitulasi Hasil belajar Siswa, Tahun 2018

Berdasarkan Tabel IV.23, pada sebelum tindakan siswa yang tuntas secara keseluruhan adalah 17 orang siswa atau dengan persentase $47,22 \%$, pada siklus I siswa yang tuntas secara keseluruhan meningkat menjadi 24 orang siswa atau dengan persentase $66,66 \%$, dan pada siklus II siswa yang tuntas secara keseluruhan adalah 31 orang siswa atau dengan persentase $86,11 \%$. Perbandingan hasil belajar siswa dari sebelum tindakan, siklus I, dan siklus II juga dapat dilihat pada gambar berikut:

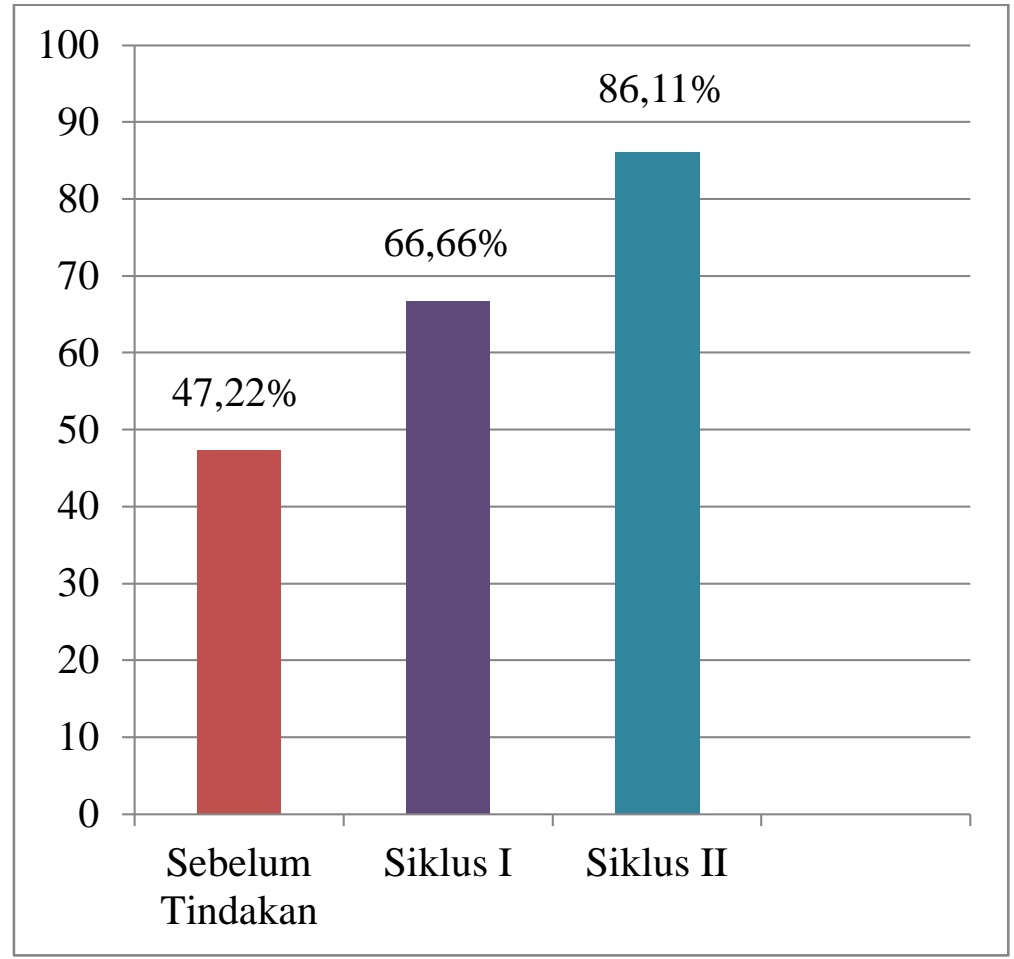

\section{Gambar 4. Grafik Rekapitulasi Perbandingan Hasil Belajar Siswa Sebelum Tindakan Siklus I dan Siklus II}

Berdasarkan hasil penelitian yang peneliti lakukan, bahwa penelitian hasil belajar siswa pada mata pelajaran matematika meningkat dari sebelum tindakan $47,22 \%$, Siklus I 66,66\%, dan Siklus II 86,11\%. Jadi, model pembelajaran student facilitator and explaining sangat perlu dilakukan karena model pembelajaran student facilitator and explaining dapat meningkatkan hasil belajar siswa. 


\section{KESIMPULAN DAN SARAN}

\section{Kesimpulan}

Berdasarkan hasil penelitian ini dapat disimpulkan bahwa penerapan model pembelajaran student facilitator and explaining dapat meningkatkan hasil belajar siswa kelas V pada mata pelajaran Matematika di Sekolah Dasar Negeri 164 Pekanbaru. Hal ini dapat dilihat bahwa hasil belajar Matematika siswa sebelum tindakan hanya mencapai 47,22\%. Setelah dilakukan tindakan kelas pada siklus I, hasil belajar siswa meningkat menjadi 66,66\% atau tergolong "Kurang". Sedangkan pada siklus II terjadi peningkatan menjadi 86,11\% atau tergolong "Sempurna". Artinya indikator keberhasilan yang telah ditetapkan yaitu 75\% telah tercapai.

\section{Saran}

Bertolakdaripembahasanhasilpenelitiandankesimpulan di atasberkaitanpenerapan model pembelajaran student facilitator and explaining yang telahdilakukan, makapenelitimemberikan saran-saran sebagaiberikut: (1) Melalui model pembelajaran student facilitator and explaining guru berharapdari 36 orang siswahanya 17 orang siswaatau 47,22\% yang telahmencapainilai KKM yang ditetapkanyaitu 75. (2) Melalui model pembelajaran student facilitator and explaining guru berharapdari 36 orang

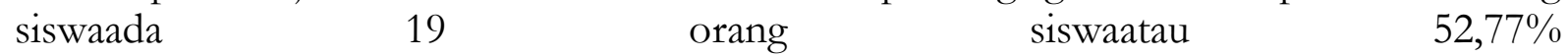
siswamasihsulitdalammenjawabsoalulangandenganbenar, agar bisamenjawabsoalulangandenganbenar. (3) Dari 36 orang siswahanya 5 orang siswaatau $13,8 \%$ yang mengajukanpertanyaanketikadiberikankesempatanuntukbertanyaoleh guru. Setelahditerapkan model pembelajaran student facilitator and explaining guru berharapbanyaksiswa yang mengajukanpertanyaan.

\section{REFERENSI}

Alex Sobur.(2003). Psikologi Umum. Bandung: CV Pustaka Setia.

Anas Sudjino. (2004). Pengantar Statistik Pendidikan. Jakarta: Raja Grafindo Persada.

Aunurrahman. (2009). Belajar dan Pembelajaran. Bandung: Alfabeta.

BSNP.(2007). Pedoman Penilaian Hasil Belajar di Sekolah Dasar. Jakarta: Depdiknas.

Depdiknas (2004). Rambu-rambu Penetapan Ketuntasan Belajar Minimum dan Analisis Hasil Pencapaian Standar Ketuntasan Belajar. Jakarta: Pusat Kurikulum Balitbang Depdiknas.

E. Mulyasa. (2011). Kurikulum Tingkat Satuan Pendidikan. Bandung Remaja Rosdakarya. Istarani. (2014). 58 Model Pembelajaran Inovatif. Medan: Media Perkasa.

Mardia Hayati. (2014). Desain Pembelajaran. Pekanbaru: CV Mutiara Pesisir Sumatra.

Masnur Muslich.(2011). Melaksanakan Penelitian Tindakan Kelas Itu Mudah. Jakarta: Bumi Aksara.

Mimi Hariyani \& Melly Andriyani.(2013).Pembelajaran Matematika SD/MI. Pekanbaru: Benteng Media.

Mubibbinsyah.(2013). Psikologi Pendidikan. Bandung: PT. Remaja Rosdakarya. 
Ngalim Purwanto. (1987). Psikologi Pendidikan. Bandung: Remaja Rosdakarya.

Oemar Hamalik. (2005). Kurikulum dan Pembelajaran. PT. Bumi Aksara.

Purwanto. (2013). Evaluasi Hasil Belajar. Yogyakarta: Pustaka Belajar.

Ramayulis. (1990). Pengajaran Matematika SD. Jakarta: Kalam Mulia.

Sardiman. (2007). Interaksi dan Motivasi Belajar Mengajar. Jakarta: Raja Grafindo Persada.

Suharsimi Arikunto. (2006). Prosedur Penelitian Suatu Pendekatan Praktek. Jakarta: Rineka Cipta. 